
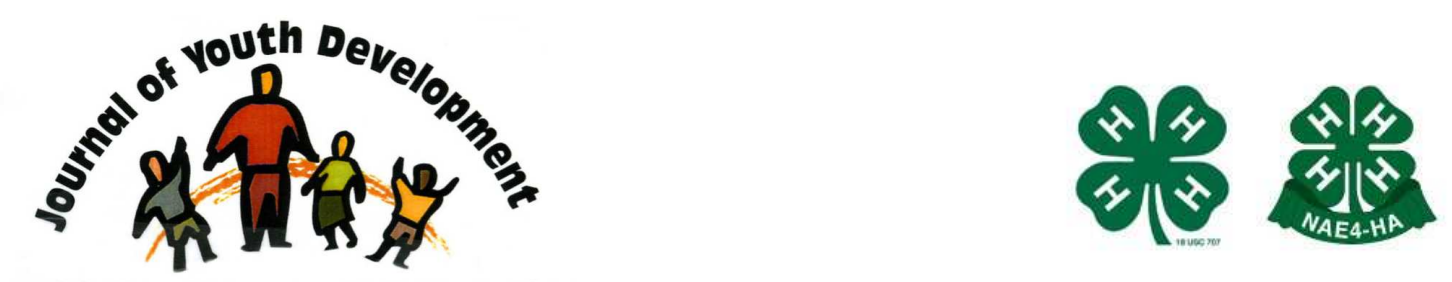

Bridging Research \& Practice

\title{
Promoting Character and Resiliency among Elementary School Students: An Assessment of the CARE Now Program
}

\author{
Eddie Hill \\ Human Movement Sciences Dept. \\ Old Dominion University \\ Norfolk, VA \\ ehill@odu.edu \\ Tammi Milliken \\ Counseling and Human Services Dept. \\ Old Dominion University \\ Norfolk, VA \\ Jennifer Goff \\ CARE Now Site Director \\ Human Movement Sciences Dept. \\ Old Dominion University \\ Debbie Clark \\ CARE Now Site Director \\ Counseling and Human Services Dept. \\ Old Dominion University
}




\title{
JOURNAL OF YOUTH DEVELOPMENT \\ bridging research and practice

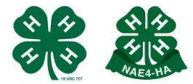

Bridging Research \& Practice

Volume 10, Number 1, Spring 2015

Article 151001PA001

\section{Promoting Character and Resiliency among Elementary School Students: An Assessment of the CARE Now Program}

\author{
Eddie Hill and Tammi Milliken \\ Old Dominion University \\ Jennifer Goff and Debbie Clark \\ CARE Now
}

\begin{abstract}
Youth, especially in inner-city areas of the country, are in need of effective, outcome-based camp programs when school is not in session. Character and Resiliency Education (CARE) Now (CN) is a comprehensive in- and afterschool program designed to promote academic enrichment through positive youth development with a focus on enhancing character and resiliency. In the summer of 2013, CN was adapted to create a three-week long day camp at a high-needs elementary school in eastern Virginia. Using theoretically-based and outcome focused programming, CN was widely praised for its effectiveness among youth in this summer camp. To assess its impact, a mix-method approach was used, producing desirable results. Consequently, the supporting organization moved forward to fund CARE Now for a year-long program at the same school.
\end{abstract}

\section{Introduction}

Many youth development based programs target sixth-grade students because they have the greatest need because of the challenges inherent with the transition to middle school. Baseline data for [some] sixth graders during recent academic years indicated that math Standards of Learning (SOL) pass rates were $46.0 \%$ with African American students passing at $32.8 \%$ and White students at 70.8\% (Virginia Department of Education, 2012). Not only do these scores reflect an overall fail rate, they also illuminate a significant discrepancy between African American and White students. Traditionally, the Character and Resiliency Education (CARE) Now (CN) program is a comprehensive in- and afterschool program designed to promote academic achievement, particularly in math, through positive youth development focused on enhancing 
character and resiliency. In math classes and throughout afterschool activities, the CARE Now program focuses on the enhancement of character and resiliency because of their established, inextricable link to academic achievement and positive youth development. Applying the Positive Behavior Interventions and Supports model (PBIS) CARE Now relies on three levels of intervention: universal, secondary and tertiary. At the universal level, large-group activities are provided to all students; at the secondary level, small-group interventions are provided to students with greater risk of academic failure; and at the tertiary level, students with greater socio-emotional disruption are provided individual attention. Using the character and resiliency traits as a means for socio-emotional support both in and out of the classroom provides students with the skills needed for academic success, particularly in the area of math. The CARE Now program also provides a highly effective service learning component for Old Dominion University college students.

In 2012, CARE Now directly contributed to Old Dominion University being named to President Obama's Higher Education Community Service Honor Roll by the Corporation for National and Community Service (CNCS) and the U.S. Department of Education. The Honor Roll recognizes the nation's leading colleges and universities, students, and faculty and staff for their commitment to bettering surrounding communities through community service and service learning. "Through service, these institutions are creating the next generation of leaders by challenging students to tackle tough issues and create positive impacts in the community," said Robert Velasco, acting CEO of CNCS. "We applaud the Honor Roll schools, their faculty and students for their commitment to make service a priority in and out of the classroom. Together, service and learning increase civic engagement while fostering social innovation among students, empowering them to solve challenges within their communities" (Inside ODU: News for Faculty and Staff, April 2012).

The CARE Now program was developed by faculty from ODU's Counseling and Human Services and Park, Recreation and Tourism Studies programs in collaboration with the school district and the city's Bureau of Youth Services. The CN program is a 20 weeklong program grounded in character and resiliency. The in- and after-school with curriculum consists of activities including academic and social support. The curriculum provides supplemental math classes by trained ODU students or "advocates" as they are called, weekly classroom lessons on character and resilience, and a three-hour afterschool program utilizing intentionally designed activities aligned with topics addressed (e.g., resilience) in school. The advocates in CN are completing a class lab tied to course (i.e., Youth Development through Recreation), or completing a practicum/internship. In either case, the advocates are trained in a variety of skills from managing difficult behavior to reporting child abuse, and must complete a 12-40 hours of CARE Now training. The advocates (approximately 100 college students each semester) work within the small groups of public school students 2-3 times a week over the course of a year. The advocates use prescribed activities (i.e., cooperative teambuilding exercises) from the CARE Now curriculum to program the daily activities. The curriculum consists of 20 Weekly Activity Plans (WAP), which mirror lesson plans with measurable objectives, activities, variations, assessment, and reflective learning exercises. Each WAP is theoretically grounded, based on the four dimensions of character (e.g., honesty) and seven of resiliency (e.g., initiative). The WAPs include step-by-step instructions of the activities for the advocates to facilitate. The activities prescribed activities are practiced in the lab portion of $\mathrm{CN}$ before entering the public school portion of the program. 


\section{Camp Programming}

The American Camp Association (ACA) has been integral in supporting PYD by identifying and documenting outcomes associated with participation in organized camping. In their seminal outcomes study four domains were comprised of ten constructs of PYD and included positive identity (positive identity, independence), social skills (leadership, making friends, social anxiety, peer relationships), positive values and spiritual growth (positive values/decision making, spirituality), and thinking and physical skills (adventure/exploration, environmental awareness) (Henderson, Bialeschki, Scanlin, Thurber, Whitaker, \& Marsh, 2007). The ACA sponsored research is salient in that it provides evidence of what many practitioners already know; organized camping is beneficial to the development of youth (American Camp Association, 2005). Moreover, the ACA project provides support for organized camping as a context for change thereby helping justify and provide accountability (e.g. resources) (Sibthorp, Bialeschki, Morgan, \& Browne, 2013).

In the summer of 2013, mirroring much of the ACA's model of intentionally programming, the CARE Now program was adapted to fit a local elementary school's need for an evidence-based summer day camp. The CARE Now project was implemented in a specific elementary school of Southeast Virginia because of the students in very high need (e.g., failing academically, neighborhood turf wars, etc.). The schools are typical of many urban schools with a high number of underrepresented students who lack the basic resources and skills essential to academic success. The student populations exhibit higher-than-average rates of academic failure, truancy, higher dropout rates, disciplinary infractions, and poor relationships with school personnel, family, and the community at large. Many of the schools' students live in government-subsidized housing with $66.05 \%$ of the total school district's population and $98 \%$ of the students in the elementary school noted in this article eligible to receive free and reduced meals (Virginia Department of Education, 2012).

The CARE Now Summer Camp aimed to provide outcome-focused character and resilience programming to all rising $5^{\text {th }}$ and $6^{\text {th }}$ graders as a means to promote academic readiness and student motivation. The focus on rising $5^{\text {th }}$ and $6^{\text {th }}$ graders aimed to prepare them for the increasing academic demands of $5^{\text {th }}$ grade and the challenging transition to Middle school for $6^{\text {th }}$ graders. Old Dominion University faculty from the departments of Counseling and Human Services, and Human Movement Sciences developed CARE Now. The program aims to develop students' character because character education has been documented to increase individuals' ability to participate successfully in a democratic society (Narvaez, Bock, Endicott, \& Lies, 2004). Additionally, the program focuses on developing students' resilience based on research showing that resilient individuals have increased academic performance (Hill, Milliken, Goff, \& Gregory, 2013). The following are the [seven] resilience and [four] character traits (respectively) addressed in the Day Care Program: Relationships, Insight, Independence, Initiative, Creativity, Humor, and Values; followed by Trustworthiness, Conscientiousness, Honesty, and Rule Following. Using the Outcome-Focused Programming (OFP) model, the CARE Now summer camp was created.

The Outcome-Focused Programming (OFP) model includes four steps:

(1) outcome oriented, program goals should be identified and meaningful to the agency, the participants, and other stakeholders,

(2) theory-based program components should be intentionally structured to address the stated goals,

(3) progress toward desired goals must be assessed, and 
(4) an organization must publicize its outcomes (Tucker, \& Allen, 2008; Allen, \& Cooper, 2003).

Within the first step, program coordinators should refer to their organization's mission, vision, goals and values. A decrease in aggressive behavior (Collins, 2009) or addressing academic achievement (Nishina, et al., 2005) could be goal-oriented outcomes. The second step encourages the program developer to gather data on successful, theory-based programs that have been implemented and create a plan to develop and execute their own program. Third, the program should be evaluated. This can be done via any type of program evaluation tool including questionnaires, skill retention surveys, focus groups, or open-ended questions. The last step identifies the importance of sharing successful ideas with interested parties. Sharing of resources can be achieved in a variety of ways such as program advertisement, newspaper and journal articles, conferences, or workshops. Studies have used these theory-based traits in a variety of in and afterschool programs (Brown, Hill, Shellman, \& Gómez, 2012; Hill, \& Milliken, 2012; Hill, et al., 2007).

\section{Method}

For three weeks during the summer of 2013, CARE Now was implemented as a summer day camp. The three and a half-hour program immediately followed the morning academic based program. CARE Now served 38 rising $5^{\text {th }}$ and $6^{\text {th }}$ graders at the local high-risk elementary school. As part of a service learning initiative, Old Dominion University Human Services and Counseling, and Park, Recreation and Tourism Studies students (called Advocates) worked with the elementary students. Each day began with the Advocates joining the elementary students for lunch and building rapport. Following, the Advocates presented guidance lessons introducing the character and resiliency trait of the day. Throughout the week those traits were reinforced when working with students to solve problems, communicate appropriately, and express their feelings, all with the goal of promoting character and resiliency to enhance academic achievement. Advocates also led small- and large-group intentional recreation activities related to the character and resiliency traits noted above, and provided opportunities for individual attention.

The activities included cooperative teambuilding exercises. The components utilized a small group problem solving approach by dividing the elementary school students into three groups. Specific activities were then selected to promote the trait of the week. For example, during the day of Initiative (resiliency-based) and Honesty (character-based), the activity Key Punch was used. Key Punch is a challenge activity that allows for groups to have leaders, and followers to accomplish a task within a given timeframe. The goal, as a group, was to touch a series of numbers/math problems (in order, in the designated space) as quickly as possible with minimal errors. Key Punch was also a fun and exciting exercise that allows students to creatively solve math equations and become comfortable with numbers. This activity also promotes planning and problem-solving within a group while requiring students to listen to one another and follow through with handling conflicts. Within these groups, over the course of the three-week camp participants developed friendships through experiential education, challenge initiatives, and academic support from one another.

The CARE Now Summer Camp, operating as an add-on to summer enrichment programming, was offered three hours per day for three weeks, Monday through Thursday (July 8-11, July 1518 , and July 22-25). CARE Now Summer Camp started with the advocates joining the participants for lunch (called grub groups), and then continued directly into the program. 
The schedule was:

11:30-11:45am-Advocates check-in

11:45am-12:00pm -Advocates review day and ask questions/concerns

$12: 00$ to $12: 30$ pm-Advocates eat lunch with students

$12: 30$ to $1: 10 \mathrm{pm}$-Guidance lesson and reflection

1:10-1:30pm-Large group (if weather permit) or straight into small groups

$1: 10$ to $2: 15 \mathrm{pm}$-Small group activities

2:15 to $2: 30$ pm-Snack and reflection

2:30 to 3:30pm-Advocates join students for Entrepreneur enrichment program

$3: 25$ to $3: 30$ pm-Raffle

3:30-Students dismiss

3:30 to 3:45pm-Advocates reflect on day/ask questions, etc.

3:45pm-End of program

\section{Measurement}

This study, because of the small sample size, used a mix-methods approach. Two metrics (see below) were used to collect the quantitative data. However, the quantitative analyses needed to be interpreted with caution due to the low number of youth in the program. Exploring themes within the self-directed letters written by campers to their advocates used a qualitative approach. Collectively, these two approaches were effective at determining a variety of outcomes from the CARE Now Summer Camp.

Resiliency and Attitudes Skills Profile (RASP): The seven resiliency traits identified and described by Wolin and Wolin (1993) served as part of the theoretical foundation upon which the CARE Now program was developed. The seven traits were operationalized via the Resiliency Attitudes and Skills Profile (RASP), which consisted of a series of 40 "I - statements" with multiple inquiries about each of the seven resiliency traits. Items were measured on a 6-point, Likerttype scale, with $1=$ Strongly Disagree and $6=$ Strongly Agree. The RASP has been used in several studies, and is effective at outcome-focused programming (Brown, Hill, Shellman, \& Gómez, 2012; Hill, Brown, \& Cosnett, 2011; Hill, Milliken, Goff, \& Gregory, 2013; Hill, Gomez, \& Jeppesen, 2007).

The RASP has a reported internal consistency of .91 (Hurtes, \& Allen, 2001). Although the RASP specifically measures the seven constructs separately, the assessment shows higher levels of internal consistency used as a unidimensional measure (Hurtes, \& Allen). Hurtes and Allen reported that the RASP is also positively correlated with the Psychological Well-Being scale $(r=$ $.47)$ and negatively correlated with the Psychological Distress scale $(r=-0.22)$. Other studies have continued to test the robustness of the RASP with various findings, such as suggesting a 19-item version (Williams, Gómez, Hill, Milliken, Goff, \& Gregory, 2013). However, due to the anticipated small sample size in study the original 40-item RASP was used.

Citizenship Scale: The Citizenship Scale is a 12-item student self-report on issues of honesty, trustworthiness, rule following, and conscientiousness. It falls into James Rest's (1986) third component of moral behavior, ethical focus or motivation (other components are ethical sensitivity, ethical judgment and ethical action). Initially tested as part of a battery of items examining ethical identity, duty and citizenship in elementary school students, twelve items loaded together as one factor termed "citizenship." Items include: "You should be on time to 
school or appointment" and "It is important to support those who are following the rules." Respondents complete a 5-point Likert-type scale (never agree to always agree).

Previous research with high school and college students has found a Cronbach's reliability of .93 (Narvaez, Gardner, \& Mitchell, 2001). Narvaez, Bock, Endicott, and Lies (2004) discussed three samples: a pilot study with middle school students $(n=78)$ indicated a Cronbach alpha of .89; a separate data set from students not used in the pre-post analysis indicated a Cronbach alpha of $.92(n=412)$ whereas the experimental sample had a Cronbach's alpha of .92 $(n=479)$. In Mullen, et al., (2005) the alpha was .83. Narvaez, et al. (2004) and Mullen, et al., found that positive school climate was related to higher scores on the Citizenship Scale.

\section{Results}

\section{Description of Sample}

The CARE Now Summer Camp was available and accessible to rising $5^{\text {th }}$ and $6^{\text {th }}$ grade students at the elementary school. Of the 38 who participated, 33 students were granted permission from their parents/guardians and assented to complete the questionnaires (RASP and Citizenship) prior to participation and again at the end of the summer camp, resulting in an $87 \%$ response rate.

Of the 33 students who completed the questionnaires, only 12 (four males and eight females) of the pre- and posttest data sets could be matched. An additional 11 questionnaires were complete at pretest, and 11 at posttest, but could not be matched. Paired samples $t$-tests were used to compare participants from pretest to posttest scores. However, due the small sample size, the quantitative results need to be interpreted with caution. The results should be treated as pilot data to further support similar programs, as well as used to help influence programmatic decisions of CARE Now.

\section{Quantitative}

Results indicated an increase, but no significant difference between participants' pretest of the $\operatorname{RASP}(M=4.73, S D=.90)$ and posttest scores $(M=5.01, S D=0.89)$, with $t(10)=-2.05$, $p=.06$, with a corresponding effect size, $r_{\mathrm{pb}}=0.27$. Additionally, although a slight increase of score in the Citizenship Scale, no significant difference was found between pretest $(M=4.75$, $S D=0.28)$ and posttest $(M=4.81, S D=0.21)$, with $t(7)=-.697, p=.50$, with a corresponding effect size, $r_{\mathrm{pb}}^{2}=0.057$. There was no significant difference between males and females, although males scored higher than females at RASP pretest, but lower than females on the Citizenship pretest (see Table 1).

\section{Table 1}

t-test Results Comparing Pre and Posts test for the RASP and Citizenship Scale

\begin{tabular}{|c|c|c|c|c|c|c|}
\hline & $\mathrm{N}$ & $M$ & $S D$ & $t$ & $p$ & $r_{p b}^{2}$ \\
\hline \multicolumn{7}{|l|}{ RASP } \\
\hline Pretest & 11 & 4.73 & 0.9 & & & \\
\hline Posttest & 11 & 5.01 & 0.89 & -2.05 & 0.06 & 0.27 \\
\hline \multicolumn{7}{|l|}{ Citizenship Scale } \\
\hline Pretest & 11 & 4.75 & 0.28 & & & \\
\hline Posttest & 11 & 4.81 & 0.21 & -6.97 & 0.5 & 0.057 \\
\hline
\end{tabular}


While the results were not statistically significant, it is noteworthy to acknowledge any positive shift in scores considering the short amount of time the children participated in the camp. Gains in resilience and character, being associated with a greater capacity to cope with adversity, higher moral consciousness, and greater success academically, are of value to all students, and particularly to those faced with the challenges of poverty and instability experienced by so many of the elementary school students. Statistically significant results have been obtained each year from middle school students participating in the full academic year version of CARE Now since its inception in 2008. It is worth assessing if these significant gains can be replicated for elementary school students during the 2013-14 school year.

\section{Qualitative}

Also analyzed were qualitative data obtained through letters written by one class of 16 camp participants (see Table 2). The 16 students were asked to write letters to their Advocates about their experience of CARE Now Summer Camp. A content analysis was conducted through the coding of each letter followed by an assessment of sub-themes. These sub-themes combined into four overarching themes. The analysis was audited by a colleague as a means to enhance reliability of the results. The overarching themes that emerged included Experience of Learning, Appreciation of Activities/Experiences, Experience of Advocates, and Feelings Related to the Program. Related to Experiences of Learning, students addressed the sub-themes of learned topics to use now, and learned topics to be used in the future. Specifically, 22 comments were made in the letters addressing these sub-themes, with nine specifically focusing on the value of the Five-Finger Contract. The Five-Finger Contract, used in many adventure education programs, is tool used to create group rules and norms. Each finger stands for statement/expectation that all students understand and agree upon and is as follows: the pinky stands for sensitivity; the ring finger stands for commitment; the center finger stands for respect; the pointer finger stands for responsibility; the thumb stands for encouragement. Each finger is described to the group by the facilitator and students express what this means to them. It can also be used as a nonverbal reminder of group norms. One student said, "The Five-Finger Contract did a lot for me. I can use it when I get older."

Regarding Appreciation of Activities/Experiences, students addressed the sub-themes of games/lessons/activities, snacks, and going outside. Students made 25 comments related to these sub-themes, focusing on how much fun they were, how beneficial they were, and how much they liked them. A student made the following comment: "Thank you for letting us do activities and going outside. I love when y'all gave us snacks. I liked when we played games. I'm just am thank for everything" [SiC].

Related to respondents' Experience of Advocates, the sub-themes of the Advocates being nice, helpful, and spending time with them emerged. The letters contained 13 comments related to this theme. A student said, "Thank you for spending time with us." While another said, "You are the most awesome people I have ever met."

Finally, with regard to Feelings Related to the Program, 21 statements were made with regard to students experiencing CARE Now Summer camp as fun, being thankful for the experience, and feeling as though they will miss the program and the Advocates. A student is quoted as saying, "Thank you for spending time with us. Thank you for giving us snacks. Thank you for playing games and when we go outside you gave us water. Thank you for doing good thing and stuff with us." Another said the following: "I am really going to miss you all when you leave." 


\section{Table 2}

Themes and Subthemes by Occurrence

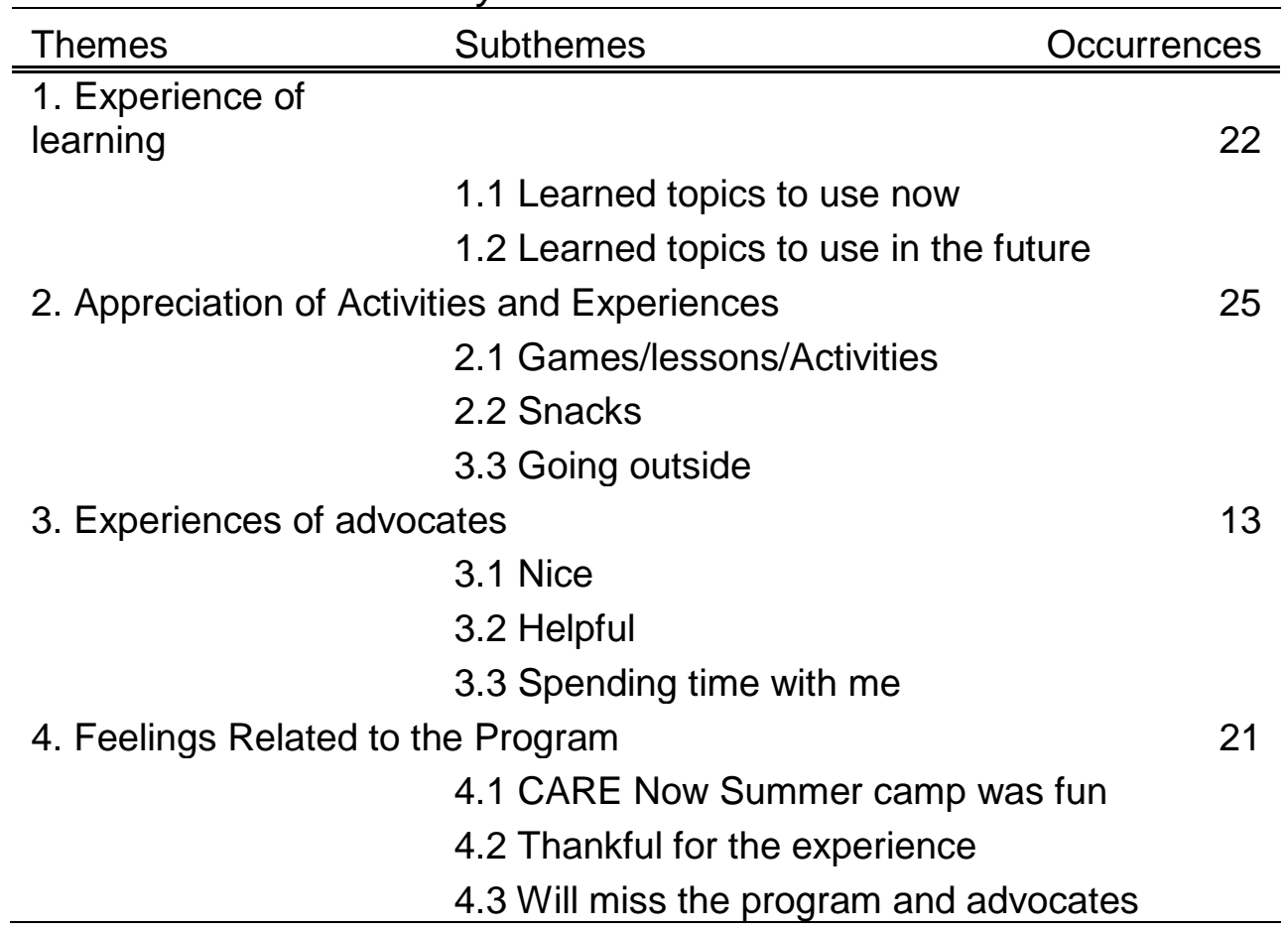

An additional theme emerged that is worth noting. Not one of the 16 letters mentioned negative experiences of CARE Now Summer Camp, the Advocates, activities, or experiences. The results indicate that the students who participated in CARE Now Summer Camp had a very positive impression of the program. It is evident that they took away valuable lessons, experienced positive bonds with supportive adults, and had fun in the process. Future qualitative evaluations can expand on these findings to include more participants' letters as well as written feedback about the programming from teachers and administrators at PB Young.

\section{Discussion}

The foundation of Positive Youth Development (PYD) originates from several fields of study to include positive psychology, developmental psychology, and prevention sciences, (Lerner, Almerigi, Theokas, \& Lerner, 2009), yet the strength-based approach to adolescence has intuitively been used by youth workers in the recreation (e.g. camps) for some time (Thurber, Scanlin, Scheuler, \& Henderson, 2006). Furthermore, the call for evidence-based practices (e.g., Outcome-focused Programming) among youth serving organizations is on the rise. This study's summer CARE Now camp showed tremendous potential as an effective program to serve students during the summer when programming tends to be scarce. The elementary school was so pleased with the summer program that the principal requested CARE Now return during the school year to function as an in- and afterschool program. CARE Now was funded to continue its work in the school for the 2013-2014 school year and has served all $3^{\text {rd }}$ through $5^{\text {th }}$ grade students. Data were collected for continued assessment of the program's impact.

As indicated from the results of the research presented in this article, programming such as CARE Now can contribute positively to children's development both socio-emotionally and academically. Results such as these are necessary to further support the relationship between 
emotional intelligence and academic achievement. The results may be used to substantiate inclusion of intentional supplementary programming in any academic setting. Thus, it is recommended that organizations aiming to promote academic achievement among youth through school-based programming make efforts to utilizing theoretically-based and outcome focused approaches that serve the total child. Likewise, it is recommended that data is collected as a means to assess impact on both socio-emotional and academic markers. In addition to further substantiating the link between non-academic programming and achievement, positive results promote support for program funding and retention.

Future studies should continue to rigorously test the psychometric properties of the measurements used, as well as consider some of the identified American Camp Association measurements (e.g., Youth Outcomes Battery) to demonstrate evidence-based practices. Summer camps and recreation programs have the ability to impact youth in areas such as diabetes management (Taylor, Piatt, Hill, \& Malcolm, 2012), self-esteem (Marsh, 1999), resiliency (Brown, Hill, Shellman, \& Gómez, 2012), and other areas society considers important in helping to create assets to our community. Collectively, some of these approaches should help determine the larger impact of camp and other youth serving organizations. This in return will lead to further support and need for professionals trained to work among youth with the knowledge and skills of the positive youth development movement.

Acknowledgement: This CARE Now summer camp was possible thanks to a funding from the United Way of South Hampton Roads Women's Leadership Council.

\section{References}

Allen, L.R., \& Cooper, N.L. (2003). Benefits based programming curriculum manual. Ashburn, VA: National Recreation and Park Association.

American Camp Association. (2013). Camp trends: Enrollment. Retrieved from: http://www.acacamps.org/media-center/camp-trends/enrollment

Brown, L., Hill, E., Shellman, A., \& Gómez, E. (2012). Positive youth development: A resiliencybased afterschool program case study. Journal of Youth Development: Bridging Research and Practice, 74$), 50-62$.

Henderson, K., Bialeschki, D., Scanlin, M., Thurber, C., Whitaker, L., \& Marsh, P. (2007). Components of camp experiences for positive youth development. Journal of Youth Development: Bridging Research and Practice, 1(3), 2-12.

Henderson, K., Bialeschki, D., \& James, P. (2007). Overview of camp research. Child \& Adolescent Psychiatric Clinics of North America, 16(4), 755-767.

Hill, E., Milliken, T., Goff, J., Gregory, N. (2013). Promoting Character and Resiliency through Programming. Parks \& Recreation, April, 38-39.

Hill, E., \& Milliken, T. (2012). Benefits based programming: A collaborative model serving diverse populations. National Recreation and Park Association Congress and Exposition, Anaheim, CA. 
Hill, E., Gomez, E., \& Jeppesen, G. (2007). Adolescent resiliency: A multidisciplinary approach. Annual in Therapeutic Recreation (Vol. XIV), 59-73.

Hill, E., Brown, L., \& Cosnett, E. (2011). Creating a benefits-based afterschool program. The Voice, Winter, 16-18.

Hill, E., Milliken, T., Goff, J., Gregory, N. (2013). Promoting Character and Resiliency through Programming. Parks \& Recreation, April, 38-39.

Hurtes, K.P., \& Allen, L.R. (2001). Measuring resiliency in youth: The resiliency attitudes and skills profile. Therapeutic Recreation Journal, 35(4), 333-347.

Lerner, R., Almerigi, J., Theokas, C., \& Lerner, J. (2009). Positive youth development: A view of the issues. Journal of Early Adolescence, 25(1), 10-16.

Marsh, P. (1999). Does camp enhance self-esteem? Camping Magazine, 72(6), 17-21.

Mullen, G., Turner, J., \& Narvaez, D. (April, 2005). Student Perceptions of Climate Influence Character and Motivation. American Educational Research Association, Montreal.

Narvaez, D., Bock, T., Endicott, L., \& Lies, J. (2004). Minnesota's Community Voices and Character Education Project. Journal of Research in Character Education, 2, 89-112.

Narvaez, D., Gardner, J., \& Mitchell, C. (August, 2001). Community bonding: A protective factor for at-risk behaviors and attitudes. American Psychological Association, San Francisco.

Nishina, A., \& Juynnen, J. (2005). Daily Reports of Witnessing and Experiencing Peer Harassment in Middle School, Child Development 76 (2) 435-450.

President's Higher Education Community Service Honor Roll. (2012). Retrieved May 1, 2012 from http://www.nationalservice.gov/about/initiatives/honorroll.asp.

Rest, J. (1986). Moral development: Advances in research and theory. New York, NY: Praeger.

Sibthorp, J., Bialeschki, D., Morgan, C., \& Browne, L. (2013). Validating, norming, and utility of a youth outcomes battery for recreation programs and camps. Journal of Leisure Research, 45(4), 541-536.

Taylor, J., Piatt J., Hill, E., \& Malcolm T. (2012). Diabetes Camps and Self-Determination Theory: Controlling Glycemic Level in Youth with Type 1 Diabetes. Annual in Therapeutic Recreation (Vol. XX), 46-58.

Thurber, C., Scanlin, M., Scheuler, L., \& Henderson, K. (2006). Youth development outcomes of the camp experiences: Evidence for multidimensional growth. Journal of Youth and Adolescence, 36, 241-254. doi 10.1007/s10964-006-9142-6.

Tucker, T.W., \& Allen, L.R., (2008). Implementing OFM in municipal parks and recreation departments. In B.L. Driver (Ed.), Managing to optimize the beneficial outcomes of recreation (pp. 75-94). State College, PA: Venture Publishing. 
Virginia Department of Education. School Report Card. Retrieved May 1, 2012 from https://p1pe.doe.virginia.gov/reportcard/report.do?division=118\&schoolName=324.

Williams, T., Gómez, E., Hill, E., Milliken, T., Goff, J., \& Gregory, N. (2013). The resiliency and attitudes skills profile: An assessment of factor structure. Illuminare: A Student Journal in Recreation, Parks, \& Leisure Studies, 11(1), 16-30.

Wolin, J., \& Wolin, S. (1993). The resilient self: How survivors of troubled families rise above adversity. New York: Villard books.

(C) Copyright of Journal of Youth Development $~$ Bridging Research and Practice. Content may not be copied or emailed to multiple sites or posted to a listserv without copyright holder's express written permission. Contact Editor at: patricia.dawson@oregonstate.edu for details. However, users may print, download or email articles for individual use.

ISSN 2325-4009 (Print); ISSN 2325-4017 (Online) 